\title{
https://doi.org/10.48009/2_iis_2007_45-52 \\ EMPIRICALLY TESTING FACTORS THAT DRIVE ICT ADOPTION IN AFRICA AND OECD SET OF NATIONS
}

\author{
Kallol Bagchi, University of Texas at El Paso, kbagchi@utep.edu \\ Godwin Udo, University of Texas at El Paso, gudo@utep.edu
}

\begin{abstract}
This study investigates factors that affect the adoption of information and communications technology (ICT) in Africa. The study also compares the ICT adoption factors in African nations with that of developed nations, represented by the Organization of Economic and Cooperative Development (OECD) over a period of over 21years. Using a large set of data from World Bank and pooled regression analysis, the results show that economic development, education/training, and infrastructures play a significant role in ICT adoption. The effects of these factors could be similar or different on developed and developing nations depending on the specific factor considered.
\end{abstract}

Key Words: ICT Adoption, OECD, Africa, Pooled Regression, Adoption Factors, Information

Infrastructure

\section{INTRODUCTION}

Economies that implement Information and Communications technology (ICT) successfully have benefited greatly from its impact in all aspects of business transactions [10]. The implementation of ICT in the thirty nations comprising the Organization of Economic and Cooperative Development (OECD) has been impressive when compared to other nations of the world. So this set of nations can be used as a benchmark for comparisons, as is done in the present study. The focus of this study is the state of ICT diffusion in Africa and what causes it. African nations are lagging severely in ICT adoptions despite the benefits from ICT experienced by others. As rightly pointed out by Shibanda and Musisi-Edebe [21], African countries need to accept ICT as a priority area for development and hence invest adequately in it which is to say Africa has to promote its economic development through the use of ICT. Danowitz et al [7] had earlier pointed out that the use of ICT in North Africa is essential for efficient business practices; improving living standards, literacy and trade. Thus important questions are why are African nations lagging in ICT adoption as widely reported and what are the major factors affecting ICT adoption in this part of the world?
Although it is common knowledge that African nations are lagging the rest of the world in technology adoption [24], few empirical studies have investigated the factors affecting ICT adoption in this part of the world in detail. The purpose of this study is to look at the factors discussed in the existing literature as important determinants of ICT adoption among nations in detail, use World Bank database [27] to empirically test the importance of some of these factors by comparing their affect on ICT adoption in Africa versus the more developed countries as represented by the OECD nations.

\section{THE THEORETICAL MODEL}

ICT adoption can be studied from various viewpoints [9, 12]. As Kwon and Zmud [12] pointed out, five levels of factor models exist in ICT adoption/diffusion literature. These are: innovation or technical (ease of use, usability etc), organizational (specialization, centralization etc.), task-level (uncertainty, autonomy etc.), environmental level (heterogeneity, competition) and individual level (job tenure, education etc.). This paper introduces factors that are valid at a national level.

As pointed out by Toussea-Oulai and Ura [23], there are many possible national-level factors determining the adoption of ICT in developing countries: infrastructure, myths associated with computer installations, lack of national policy on ICT development, technology supply problems, scarcity of human resources, education problems, and economic factors. Wilson III and Wong [26] observed that a policy and institutional framework is needed to explain the diffusion of ICT in Africa. In another study of African and Latin American nations, Wallsten [25] observed that regulation had no impact on mainline telephone penetration. The prevailing individual nation conditions (economic, cultural, social, and political) also should be considered when investigating ICT adoption in African nations. Mwesige [15] concludes that factors including poverty, the high costs of computers and telephones and lack of education have severely limited the penetration of the Internet in Uganda and possibly other African nations. The technology diffusion model of Caselli and Coleman [5] also point out many of these factors for ICT diffusion. 
Thus the process of ICT adoption in developing nations has been addressed by several authors and has been summarized by Bruno et al., [4]. They identify several factors that hinders ICT growth in developing nations. These are Infrastructure, business environment (financial, legal), social factors (such as poverty, illiteracy, urbanization level), educational factors and cultural environment. Previous research also discusses these various factors, as outlined below.

\section{Business Environment}

According to Montealegre [14], the main difference between the developed and less developed countries, in terms of ICT adoption, is the business environment. The fragile business environment of the less developed countries makes it different for the ICT adoption process and model of the developed countries to be effective. Therefore, the ICT adoption model that would be useful in less developed countries needs to account for the distinctive nature of the business environment while learning from the mistakes of the developed countries [2]. Existing financial institutions such as banking play a role in ICT adoption.

\section{Infrastructure}

As pointed out by Toussea-Oulai and Ura [23] and Mwesige [15], poor basic infrastructures is a barrier to ICT adoption in developing nations. To properly adopt and use ICT, the basic infrastructural requirements include electricity and educated workers. Also, commitment from the government and other policy makers should be put in place. It has been observed that many African countries have a long way to go before securing a steady supply of electricity [11]. ICT adoption can only remain a dream to such a nation.

\section{Social and Economic Structure}

Social development (including political) and economic infrastructure play a role in ICT adoption [22]. Thus personal income (GDP per capita), inflation, income inequality etc. may play a role for developing nations. A wide difference in these structures persists among the nations of Africa. For example, in the year 2000, for Sierra Leone, the GDP per capita (also referred to as GDP in this article) was 148 (in U.S. 1995\$ value) and for Gabon it was 4378. Inflation also varied widely in the year 2000, with Equatorial Guinea having $52.17 \%$ and Ethiopia registering only $1.4 \%$.
Education. Human resources in form of existing pool of ICT personnel contribute to ICT adoption. High illiteracy rate may hinder such adoption [18]. In Africa itself, illiteracy varies widely from one nation to another. For example, in the year 2000 the illiteracy rate in Burkina Faso was $76 \%$ and in South Africa it was only $16 \%$.

\section{Cultural Environment}

National culture may play a role in ICT adoption [3, 16]. Using the Myers and Tan [16] approach, culture can be viewed as dynamic and emergent in the ICT adoption context.

To summarize, there are numerous factors as outlined by the set of previous studies discussed above which may be worthy of further study and empirical testing. However, most of these studies are limited to a few African nations and over a limited period of time (often a single year). One needs to test these factors for the entire set of African nations over a long period of time to draw any firm conclusion. Second, there is an acute paucity of studies that compares the factors for developing and developed nations. This is important, as developing nations may need to examine what are the real barriers to ICT adoption and how and where to make changes that will enable them to follow the path of developed nations. This study attempts to fill these gaps in existing literature. Considering the fact that no two less developed nations are alike [2], we need to find out the most common factors of adoptions that can be true for all African developing nations. This study attempts to do that; however, due to practical considerations (paucity of data) and existing empirical evidence, we selected from the literature only a few of the most important factors to be tested in this study. These are infrastructural variables (such as electricity level captured by its surrogate: TV adoptions per 1000, existing ICT adoption), social and economic structure (personal income, inflation, income inequality), and education (illiteracy rate) as shown in Figure 1. Next we more clearly define the major variables addressed in this case.

\section{The Dependent Variable: ICT Adoption}

As mentioned earlier, the dependent variable in this study, ICT adoption, is widely accepted as an important factor for economic development. For the purpose of this study, the components of ICT considered are mainline telephones and personal computers (PC). These two components have been selected to represent ICT because they have been 
addressed more frequently in the literature thus enabling a broader empirical test. Another reason for selecting these technologies is the availability of empirical data from the World Bank database without which this empirical test would not be possible. Adoption in this case is measured by the number of mainline telephones and PCs per 1000 people in a given

nation.

Figure 1. The ICT adoption Framework

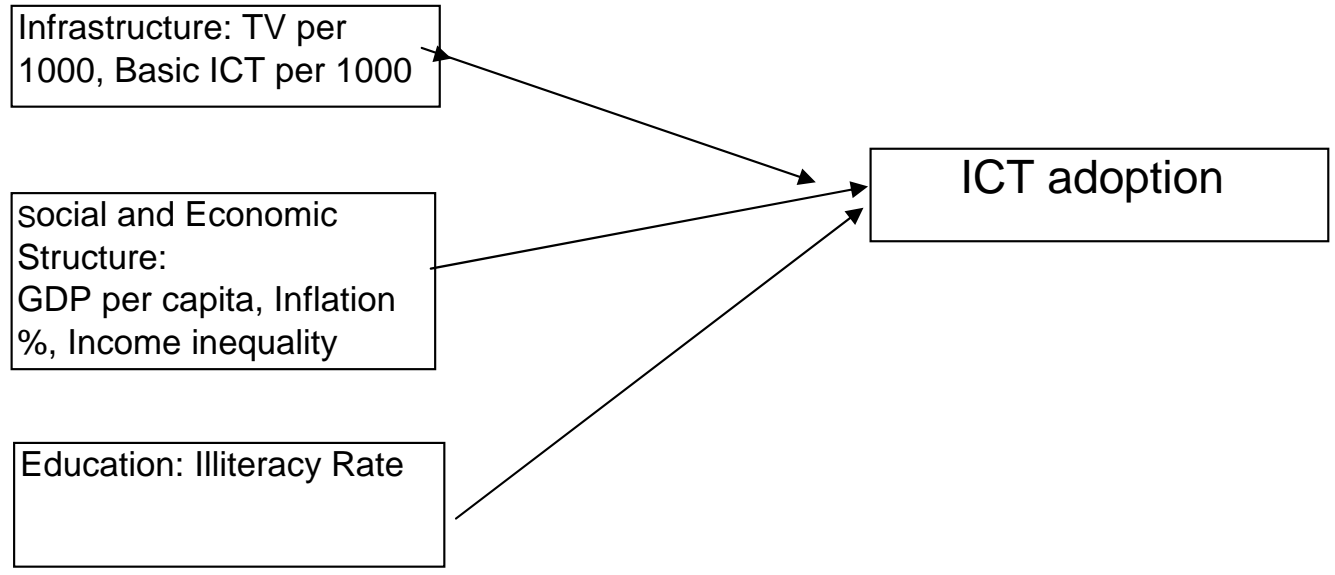

\section{The Independent Variables and Related Hypotheses}

Gross Domestic Product (GDP): The standard definition of GDP used here requires no further elaboration. Chin et al., [6] observed that economic indicators such as GDP per capita may play a role in ICT adoption. In the context of telecommunications technology, GDP per capita has been used as a control variable in some studies. It is postulated that GDP growth is directly related to any ICT adoption for OECD nations.

For certain new ICTs such as PCs, nations with low GDP per capita may try to leapfrog the ICT barrier by adopting this technology, thus bypassing the adoption of traditional mainline telephones. Thus GDP growth for African nations is expected to be directly related to the adoption of traditional ICT such as mainline telephones; and

GDP growth for African nations is expected to be inversely related to the adoption of newer ICT such PCs.

\section{Monetary Inflation}

The role of inflation is a controversial one. Some scholars think inflation decreases the economic growth; others dispute it [8]. In general, it is believed that inflation plays a negative role as it inflates price and so is not conducive to ICT growth. The relationship between ICT growth and inflation needs to be explored. It is expected that the following relationship will hold: The higher the rate of inflation, the slower the ICT adoption for all nations.

\section{Income Inequality}

Ros and Banerjee [20] have found that in poor nations, low prices may not be enough to trigger a better telecommunications adoption. One of the reasons for this could be that income inequality (that signifies the level of income disparity of a given nation) is an important index in ICT adoption. In a study of 227 academicians in two countries, Oyelaran-Oyeyinka and Adeya [17] concluded that among other factors, individual income influence adoption and use of the Internet in developing countries. Quibria et el [18] have identified income, among other factors as a key ICT adoption determinants in Asia. The more disparity there is, the less will be the adoption, as fewer people will have the buying power to purchase new ICT. It is expected that this variable will have a negative relationship with the ICT adoption. Thus it is postulated that Income inequality (Gini Index) is inversely related to ICT adoption in all nations. 


\section{Education (Literacy Rate)}

ICT adoption also requires education and training for proper use of the technology. This education and training can be simple or fairly detailed. Rice and Katz [19] identify education as one of the factors that influence the use of the Internet in the United States. Quibria et el [18] have identified education, among other factors, as a key ICT adoption determinants in Asia. Mbarika et el [13] cite acute shortage of ICT technicians as one the factors that inhibits ICT adoption in the Sub-Saharan African. Using a telephone requires less skill than using the Internet or PC. One measure of education (or lack of education) is the illiteracy rate. ICT adoption is expected to increase with better education and training. To test the effect of education on adoption, the following relationship is formulated: The higher the rate of illiteracy, the slower the rate of ICT adoption in all nations.

\section{Infrastructure}

It is also conjectured that existing infrastructures of a given nation may help in adopting any new ICT [10,
24]. Toussea-Oulai and Ura [23] highlighted lack of basic infrastructures, among other factors, as a major hindrance. Adams [1] highlights the challenges facing African nations in the information age to include: deteriorating rural infrastructures, poor education, ineffective telecommunication operations, and poor governance. In the present study, television was used as an indicator of availability of a basic infrastructure, such as electricity. ICT infrastructure variables such as mainline telephones and PCs per 1000 in a given nation are also used in different regressions. Based on the literature we propose: Infrastructure development is directly related to all ICT adoption.

\section{METHODOLOGY}

Variable Measurement

The operationalization of various variables is shown in Table 1. Three economic indicators: GDP per capita, inflation rate, and income inequality (Gini Index) were used in the regression. The level of education was captured by illiteracy rate. ICT infrastructural variables were number of TVs and mainline telephones per 1000 in a given nation.

Table 1 Variable details

\begin{tabular}{|l|l|l|l|l|}
\hline \multicolumn{1}{|c|}{ Variables used } & Source & What it represents & Years & Variable Type \\
\hline GDP per cap & World Bank & GDP per capita & $1960-2000$ & Economy \\
\hline TV & World Bank & TV per 1000 & $1960-2000$ & $\begin{array}{l}\text { ICT } \\
\text { Infrastructure }\end{array}$ \\
\hline Illiteracy Rate & World Bank & Illiteracy Rate & $1960-2000$ & Education \\
\hline Inflation & World Bank & Inflation Rate & $1960-2000$ & Economy \\
\hline GINI INDEX & World Bank & $\begin{array}{l}\text { Gini Index representing } \\
\text { Income Inequality }\end{array}$ & $1964-1996$ & Economy \\
\hline PC & World Bank & PC used per 1000 & $1980-2000$ & $\begin{array}{l}\text { ICT } \\
\text { Infrastructure }\end{array}$ \\
\hline Mainline Telephones & World Bank & Telephone per 1000 & $1960-2000$ & $\begin{array}{l}\text { ICT } \\
\text { Infrastructure }\end{array}$ \\
\hline
\end{tabular}

\section{Data Source and Analysis Procedures}

The data on various ICT adoptions were collected from the World Bank database (2003). Two ICTs were selected for this study including mainline telephones and personal computers (PC). The Internet was not included as it directly depends on basic telephony access. The telephone and the PC are two most important computing and communication gadgets that have been adopted all over the world, with varying degree of success. These two basic information technology products are proving to be more expensive in Africa than in the developed world [13]. Other sophisticated information technology products are adopted only sparsely in Africa. These technologies, in combination, can therefore capture the major information technology adoption trends in Africa, at least in the early stages of ICT diffusion.

All nations were selected from the African continent and OECD group of nations. The telephone data were available from 1960 - 2001. PC data were available from 1980 - 2001. We selected a comparison scheme over a range of years, to represent dynamic changes over a period of time. Studies made over a single year

may not capture these changes. The data set had missing pertinent data related to some variables. A 
list-wise deletion of data scheme was used in the regression for deleting such missing data. The usable data set was further reduced when other variables were combined and pooled. The African set of 53 nations contained 2310 observations (cases). The OECD set of 30 nations contained 1260 observations, including the missing data. Previous studies have considered only smaller regional samples. It can also be noted that by combining the dynamics of time and a larger number of nations, we make sure that the results are free from effects of time period as well as the number of nations used. Samples of these sizes can produce findings that are can be generalized and persuasive.

We used pooled cross-sectional time series data (also known as panel data in literature) and OLS multivariate regression in the present research. The data were "pooled" into a panel of time-series from different cross-sectional units. This pooled regression scheme allows us to cover significant geographical areas and time periods within the Africa and OECD set of nations. We used country and year dummies to capture the systematic differences among panel observations, resulting in a fixed effects model. Since the population may have different distributions in different time periods and for different nations, intercepts were allowed to differ across years and nations. This was done by introducing dummy variables for all but one year and all but one nation and the earliest year was chosen as the base year. Using pooled time series data yields precise estimates and test statistics with more power in the regression.

First to consider is the problem of multicollinearity, which involves correlation and association (linear or nonlinear) among independent variables. This can be reduced by grouping several variables into one or by eliminating some variables. Sometimes equivalent variables can be used to address this issue, for example, log GDP instead of GDP. The second issue is that of heteroscedasticity (variance of error terms is not constant) that can be compensated by using dummy variables. Autocorrelation is another problem, which means variables exhibit parallel changes over time. The effect of autocorrelation can be reduced by introducing a lagged version of the dependent variable in the right-hand side of the regression model.

\section{RESULTS AND DISCUSSION}

The main results from telecommunication product adoption pooled regressions are shown in Tables 2 and 3. Several elements of results are of particular interest and are discussed below. First, GDP per capita, as expected is positive and significant for OECD nations for all technologies. This result supports what we postulated earlier and is in line with earlier research [4]. This implies that rich nations adopt more technologies. For African nations, GDP per capita is positive and significant for mainline telephones and negative and significant for PCs, thus providing support for our conjectures. These results are also in agreement with previous research. The mainline telephone is an old technology whereas PCs are of recent origin. This shows that many low-GDP African nations are adopting PCs perhaps signaling a leapfrogging effect.

Inflation was expected to be significant as the data set contained data from early 1990s and many OECD and other nations suffered recessions during this period. However, inflation was not significant for any nation thus rejecting our assumptions made earlier. This result adds to the growing debate on the role of inflation to economic and ICT growth [8].

Next, our results show that for developed set of OECD nations, income inequalities do not play any role in ICT adoption. This is a new result. For developing nations such as the African set of nations, it plays a negative role for older technologies such as mainline telephones, thus providing partial support for our assertion and earlier research [17, 20]. However, for African nations and newer technologies such as PCs, it plays a positive role. This may be due to the fact that early adopters often tend to be rich people who can afford to buy costly new products. As expected, illiteracy rate has a negative effect for telephone regression in African nations. Many lowGDP nations are adopting new and cheaper technologies much faster, bypassing the traditional ones. The illiteracy rate is high in these low-GDP nations (see Tables 2 and 3). This fact may provide an adequate explanation of the phenomena. This result partially supports our assertion and previous research $[13,19]$.

Fourth, TV is an old technology and in a way captures the status of technology infrastructure in many nations. Thus for rich nations, TV is positively related to technology adoption in general, indicating that the effect of existing technology infrastructure is positive. This result is in line with previous research $[10,23]$. For developing nations, it is positive only for older technologies. This result is again in line with earlier research. For adoption of newer technologies, the effect is negative, as developing nations try to bypass present infrastructure to adopt new technologies, if the new technologies are more attractive and feasible. PCs are both cheaper and 
more attractive for adoptions. Thus our last assertion was partly supported.

\section{SUMMARY AND CONCLUSION}

This preliminary study is a first attempt to investigate the ICT adoption factors across the entire Africa over a significant period of time and in comparing the results with a set of developed nations (OECD). The factors in this study that are found to have significant relationships with ICT adoption are economic development (GDP, income inequality), education/training, and availability of infrastructure (including TV, PC, and mainline telephones). GDP is significant in both African and developed nations. In the case of PC adoption, all but one factor (inflation) play a significant role in determining ICT adoption in Africa compared to OECD nations in which only GDP plays a significant role. The relationships of each of the major factors that affect ICT adoption in African nations are summarized below:

Table 2. Pooled OLS Regression for Mainline Telephones: 1960-2001

Dependent Variable: Mainline Telephone

\begin{tabular}{|r|r|r|r|r|}
\hline & \multicolumn{2}{|c|}{ OECD Set of Nations } & \multicolumn{2}{|c|}{ African Set of Nations } \\
\hline Variables & $\begin{array}{r}\text { Coeffici } \\
\text { ent }\end{array}$ & T (p-value) & Coefficient & T (p-value) \\
\hline GDP per cap & .832 & $8.946(.0000)$ & .565 & $11.35(.0000)$ \\
\hline TV & .132 & $2.35(.02)$ & .364 & $13.875(.0000)$ \\
\hline Illiteracy Rate & .084 & $1.084(.28)$ & -.223 & $-.3 .161(.002)$ \\
\hline Inflation & .041 & $1.536(.126)$ & .010 & $.654(.513)$ \\
\hline Gini Index & -.065 & $-1.535(.127)$ & -.146 & $-3.727(.0000)$ \\
\hline Constant & -- & $3.44(.001)$ & -- & $3.161(.002)$ \\
\hline Adj R & .94 & & .90 & \\
\hline F-statistic & 91.61 & & 117.6 & \\
\hline No. of Observations & 220 & & 129 & \\
\hline Significant Year Variables & 26 & & 20 & \\
\hline $\begin{array}{l}\text { Significant Country } \\
\text { Variables }\end{array}$ & 4 & & & 1 \\
\hline
\end{tabular}

Table 3. Pooled OLS Regression for PC: 1980-2001 Dependent Variable: PC

\begin{tabular}{|c|c|c|c|c|}
\hline & \multicolumn{2}{|c|}{ OECD set of nations } & \multicolumn{2}{|c|}{ African set of nations } \\
\hline Variables & $\begin{array}{l}\text { Coeffici } \\
\text { ent }\end{array}$ & $\mathrm{T}$ (p-value) & Coefficient & $\mathrm{T}$ (p-value) \\
\hline GDP per cap & 2.719 & $6.79(.0000)$ & -1.62 & $-6.56(.0000)$ \\
\hline Mainline Telephones & .003 & $.013(.989)$ & 2.044 & $10.77(.0000)$ \\
\hline TV & -.005 & $-.04(.968)$ & -.466 & $-5.26(.0000)$ \\
\hline Illiteracy Rate & .339 & $1.03(.31)$ & 1.74 & $5.66(.000)$ \\
\hline Inflation & .085 & $.934(.353)$ & -.004 & $-.081(.936)$ \\
\hline Gini Index & -.067 & $-.407(.685)$ & 1.31 & $6.8(.000)$ \\
\hline Constant & -- & $-414(.680)$ & -- & $-6.05(.0000)$ \\
\hline Adj $R^{2}$ & .835 & & .852 & \\
\hline F-statistic & 22.48 & & 25.11 & \\
\hline No. of Observations & 115 & & 189 & \\
\hline Significant Yr. Variables & 14 & & 19 & \\
\hline $\begin{array}{l}\text { Significant Country } \\
\text { Variables }\end{array}$ & 6 & & 17 & \\
\hline
\end{tabular}

Economic Development: Economy is a major factor for ICT adoption as demonstrated in the results of the present study. The three indicators of economic developments used in this study are GDP, inflation and income inequality. Two out of the three indicators are significant in determining ICT 
adoption in Africa. We found that GDP per capita has a significant positive influence in ICT adoption. GDP is not only significant in the case of African nations but also in the case of developed OECD nations. Per capita GDP plays a significant role in adoption in both regions. Income inequality also has a significant relation with ICT adoption but inflation is not significant. With developed nations, neither inflation nor income inequality plays a significant role in

determining ICT adoption. This result confirms what scholars [10] have already observed which is that low-GDP nations who struggle to provide its citizens with basic life necessities, would not be able or willing to spend much resources on costly and old information technology. Even though such authors as Ros and Banerjee [20] have maintained that ICT creates new markets and also provides opportunities for the existing markets to expand, the result of this study is an affirmation of the other side of the coin. That is, information technology is more likely to be adopted by nations with healthy economic development than by low-GDP nations. In our empirical results, we find that for African nations, PC adoption is related negatively to GDP per capita. Assuming the results are not a regression artifact, several reasons can be formulated. It is possible that low-income nations have become aware of the potential use of PCs and therefore are trying to put economic resources for developing the new technology that can spur economic growth. Also, non-governmental organizations and African countries perhaps got good bargains of used computers or even new ones by shopping around the developed world. The fact that in the last few years, several organizations have donated many used PCs to African nations could also help explain this result.

\section{Infrastructure}

Infrastructure (using TV as a surrogate for electricity) is a central requirement and a prerequisite for the broad diffusion of ICT applications for social and economic ends. TV has a positive impact on Telephone adoption in Africa as well as in OECD but not on PC adoption. Instead, telephone has a positive impact on PC adoption in Africa.

\section{Education and Training of the People}

Relations between various ICT adoptions and the illiteracy rate clearly show that these are significantly correlated more so in African nations than in OECD nations. Illiteracy is positively related to adoption of PCs in developing African countries whereas in OECD nations, education has no significant relationship with the use of mainline telephones or PCs. The implication of this result is that many lowGDP nations with high illiteracy rate are adopting PCs. However, developing nations do need education and training to develop, maintain, and use the technology. The cost-effective way to do so is to develop training programs within the local institutions of learning to provide the needed education. The long term solution is to improve education level.

Although the findings have been new and insightful, like most research studies, this research has also several drawbacks: first, the measurement data it uses is secondary in nature and like most secondary data, these are susceptible to measurement errors. Second, it would be useful to investigate the effect of political factors such as political instability, social factors such as ethnic diversity, institutional factors such as corruption and government regulations and cultural influences [3]. It also would be useful to include Internet adoption in the study. We used untransformed data (for example, GDP per capita instead of log (GDP per capita)). Although our results are encouraging, experiments with other functional forms need to be investigated. We hope to extend the study to include these difficult to measure factors in our further study. Finally, the study is preliminary in nature; however, the results of this study should be of value to different groups of people who are interested in ICT transfer to developing countries.

\section{REFERENCES}

1. Adams, L. (1997). Internet connectivity and social choices in Africa. Africa

Communications, 8 (1), 16-19.

2. Austin, J.E. (1990). Managing in developing countries: strategic analysis and operating techniques, The Free Press, New York, NY.

3. Bagchi, K. (2001). The Impact of National Culture and Other National Level Indicators on It Diffusion, Ph.D Dissertation, Florida Atlantic University.

4. Bruno, G., Esposito, E., Iandoli, L., and Raffa, M. (2003). The ICT service industry in North America and the role of partnership in Morocco, JGITM, 7(3), 5-26.

5. Caselli, F., and Coleman, J. W., II. (2001). Cross-Country technology diffusion: the case of computers, NBER Working Papers 8130, National Bureau of Economic Research, Inc.

6. Chin, M.D., and Fairlie, R.W. (2004). The Determinants of the Global Digital Divide: A Cross-Country Analysis of Computer and Internet Penetration. Discussion Paper No. 881, 
Economic Growth Center, Yale University, New Haven, CT.

7. Danowitz, A.K., Nassef, Y. and Goodman, S.E. (1995). Cyberspace across the Sahara: computing in North Africa. Communications of the ACM, 38 (12), 23-28

8. Davis, G. \& Kanago, B. (1998). Inflation, inflation uncertainty, political stability and economic growth. Technical Note, Miami University.

9. Fichman, R. G. (1992). Information Technology Diffusion: A Review of Empirical Research. In Proceedings of the Twelfth International Conference on Information Systems, 195-206.

10. Gutierrez, L.H. \& Berg, S. (2000). Telecommunications liberation and regulatory governance: Lessons from Latin America. Telecommunications Policy. 24, 865-884.

11. ITU: International Telecommunications Union (2001). South Africa Country Profile.

12. Kwon, T. H.; and Zmud, R. W. (1987). Unifying the Fragmented Models of Information Systems Implementation. In J. R.Boland, and R. Hirshheim (eds.), Critical Issues in Information Systems Research, New York: John Wiley, 227251.

13. Mbarika, V. Jensen M, and Meso, P. (2002) Cyberspace across Sub-Saharan African. Communications of the ACM 45 (12), 17-21.

14. Montealegre, R. (1998). Waves of change in adopting the Internet: lessons from four Latin American countires. Information Technology and People, 11 (3), 235 - 260.

15. Mwesige, P. G. (2003). Cyber elites: a survey of internet Cafe usiers in Uganda. Telematcs \& Informatics, 21, 83-101.

16. Myers, M.D. \& Tan, F.B. (2002). Beyond Models of National Culture In Information Systems Research. Journal of Global Information Management, 10(1), 24-32.

17. Oyelaran-Oyeyka, B. and Adeya, C.N. (2003). Dynamics of adaption and usage of ICTs in African universities: a study of Kenya and Nigeria. Technovation,

18. Quibria, M.G., Ahmed, S.N., Tschang, T. and Reyes-Macasaquit, M. (2003). Digital divide: determinants and policies with special reference to Asia. Journal of Asian Economics, 13, 811825.

19. Rice, R.E. and Katz, J.E. (2003) comparing and mobile phone usage: digital divides of usages, adoption, and dropouts. Telecommunications Policy, 597- 623.

20. Ros, A. \& Banerjee, A. (2000).

Telecommunications privatization and tariff rebalancing: evidence from Latin America. Telecommunications Policy, 24 (3), 233-252.

21. Shibanda, G.G. and Musisi-Edebe, I. (2000). Managing and developing the strategy for Africa's information in global computerization. Library management, 21 95), 228-234.

22. Splettstoesser, D., and Towry-Coker, A. (1999). Model of an information and decision center for developing countries. JGIMT 2(1).

23. Toussea-Oulai, A. \& Ura, S. (1991). Information technology transfer: problems facing African developing nations. International Journal of Human-Computer Interaction, 3 (1) 79-93.

24. Udo, G. \& Edoho, F. (2000). Information technology transfer to African nations: economic development mandate. International Journal of Technology Transfer, 25, 329-342.

25. Wallsten, S. (2001). Competition, privatization and regulation in telecommunications markets in developing countries: an economic analysis of reforms in Africa and Latin America. Journal of Industrial Economics, 49 (1), 1-19.

26. Wilson III, E. \& Wong, K. (2003). African information revolution: a balance sheet. Telecommunications Policy, 27, 155-177.

27. World Bank Data base (2003). http://www.devdata.worldbank.org. 